\title{
Internação Compulsória e Vida em Cena: Subjetividades em Descompasso
}

\author{
Linccon Fricks Hernandes ${ }^{1}$

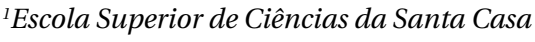 \\ de Misericórdia de Vitória, ES, Brasil. \\ Priscila Vescovi ${ }^{2}$ \\ ${ }^{2}$ Universidade Federal do Espírito Santo, ES, Brasil.
}

\author{
Túlio Alberto Martins de Figueiredo ${ }^{3}$ \\ ${ }^{3}$ Universidade de São Paulo, SP, Brasil. \\ Raquel de Matos Lopes Gentilli ${ }^{4}$ \\ ${ }^{4}$ Pontifícia Universidade Católica de São Paulo, SP, Brasil.
}

Resumo: Este artigo apresenta resultados parciais de uma pesquisa que teve por objetivo analisar vidas submetidas à internação compulsória por meio de determinação judicial. Trata-se de uma abordagem qualitativa, que utilizou entrevista despadronizada com sete jovens residentes numa comunidade terapêutica de uma cidade do interior do Espírito Santo. Observou-se, pelos relatos, que as estratégias de regulamentação da vida, seja pela judicialização, seja pela medicalização, expressam o registro biopolítico sobre corpos de sujeitos que fogem da padronização dominante. Tais práticas revelam a expressão da captura dos modos de subjetivação e das formas de subjetividade, determinando-lhes um lugar no qual a vida se mantenha reificada na perspectiva da lógica capitalística.

Palavras-chave: Internação Compulsória, Drogadição, Biopolítica, Subjetividade.

\section{Involuntary Commitment and Life on the Scene: Subjectives Out of Step}

\begin{abstract}
This article presents the partial results of a research that aimed to analyze the lives of individuals subjected to involuntary commitment by judicial determination. This qualitative research included data collected by means of unstructured interviews conducted with seven young people living in a Therapeutic Community in a city from the countryside of Espírito Santo. The reports indicate that life regulation strategies, whether through judicialization or medicalization, express the biopolitical record over the bodies of subjects who escape dominant standards. Such practices express the capture of modes of subjectivation and forms of subjectivity, determining a place where life is reified in the perspective of capitalist logic.
\end{abstract}

Keywords: Internment Compulsory, Drug Addiction, Biopolitics, Subjectivity.

\section{Ingreso Obligatorio y Vida en Escena: Subjetividades en Descompaso}

Resumen: Este artículo presenta los resultados de una investigación cuyo objetivo fue analizar las vidas insertados en un ingreso obligatorio por orden judicial. Este es un estudio cualitativo, que utilizó entrevista sin patrón con siete jóvenes residentes en una comunidad terapéutica de una ciudad en Espírito Santo (Brasil). A partir de la información de los informes, se observó que las estrategias de regulación de la vida, ya sea la legalización o la medicalización, son un registro biopolítico sobre cuerpos de sujetos que no siguen la norma dominante. Estas prácticas revelan la expresión de la captura de los modos y las formas de subjetividad, que determina un lugar donde la vida se mantiene cosificada en vista de la lógica capitalista.

Palabras clave: Ingreso Obligatorio, Drogadicción, Biopolítica, Subjetividad. 


\section{Introdução}

A dependência química como se manifesta hoje consiste num fenômeno que afeta a subjetividade das pessoas e se vincula a fatores sociais expressivos derivados da contemporaneidade, como é o caso da falta de perspectiva de vida, desemprego estrutural, tráfico de drogas, pobreza e falta de políticas públicas que ofereçam significativas oportunidades de educação, lazer e qualidade de vida para a maioria da população (Melo \& Maciel, 2016). As transformações atuais da sociedade têm estimulado alguns segmentos de jovens ao uso de drogas, fato que provoca alterações na relação com a vida social, nem sempre aceita pela família, amigos e pela sociedade.

O uso abusivo de drogas lícitas e ilícitas tem sido visto de forma preconceituosa pela sociedade, sendo os usuários considerados pessoas que escaparam da lei e das regras morais da sociedade; sobretudo aqueles que consomem drogas ilícitas, por adquirirem as substâncias de forma ilegal.

O uso abusivo de substâncias psicoativas se configura como uma questão de saúde pública, que convoca os segmentos profissionais a problematizarem alternativas clínicas possíveis em face do sofrimento dos usuários. Neste sentido, tem sido tratado como um problema que afeta a saúde mental e a segurança de pacientes e da sociedade, entretanto, se observarmos os dispositivos da Lei $\mathrm{n}^{\circ}$ 10.216, de 6 de abril de 2001 - que dispõe sobre a proteção dos direitos das pessoas com transtornos mentais -, vê-se que ocorre um redirecionamento no modelo assistencial em saúde mental no Brasil.

Tal legislação, que ficou conhecida como Lei Antimanicomial, tem origem no debate que se estabeleceu em relação à saúde pública brasileira, seguindo a trajetória participante dos movimentos sociais vinculados às lutas pela Reforma Sanitária e pela Reforma Psiquiátrica que se desenvolveram ao longo da década de 1970 (Coelho \& Barros, 2014).

Esta lei emerge num contexto de questionamento político do modelo tradicional, desumano e excludente das antigas estruturas manicomiais. Implicada em romper com este modelo asilar tradicional, visou garantir os direitos das pessoas com transtorno mental, dispondo sobre a preservação e a proteção de direitos. Conforme o art. 10, esses direitos devem ser assegurados sem discriminações de raça, cor, sexo, orientação sexual, religião, opção política, nacionalidade, idade, família, recursos econômicos, grau de gravidade, tempo de evolução do transtorno, ou qualquer outro tipo (Lei no $10.216,2001$ ).

No Brasil, o consumo não é passível de punição com prisão, mas a justiça exige que usuários contumazes sejam encaminhados para tratamento em clínicas especializadas, sobretudo porque determinadas drogas são consideradas com capacidade de atuar no psiquismo humano, provocando alterações no humor, percepção, prazer, euforia, alívio, medo, dor (Cavalcante, Alves, \& Barroso, 2008). Neste sentido, muitos jovens se tornam sujeitos à internação compulsória, pois essa tem sido uma medida judicial muito adotada visando reverter o quadro das dependências e promover a cura das alterações provocadas na vida mental e social dos usuários. Observa-se que nem sempre o que a justiça pretende de fato acontece nos referidos tratamentos especializados.

\section{Método}

Este artigo tem como objetivo apresentar resultados parciais de uma pesquisa que analisou a visão de jovens submetidos à internação compulsória por meio de determinação judicial, realizada numa comunidade terapêutica privada para o tratamento de dependentes químicos, localizada no sul do estado do Espírito Santo, entre os meses de maio e julho de 2015. Foram entrevistadas sete pessoas, consideradas jovens (de 18 a 29 anos), segundo critério etário adotado pela Organização das Nações Unidas (ONU).

Entretanto, esta pesquisa se alinha ao pensamento de Bocco (2009), que considera que forjar reflexão sobre os termos juventude/jovem possibilita que as forças ganhem mais do que formas, buscando romper com os modos instituídos de pensar juventude principalmente no que diz respeito à juventude pobre em associação com periculosidade -, que endossa uma caricatura classista de sujeitos potencialmente perigosos; frequentemente associados ao cometimento de atos infracionais e ao uso de substâncias psicoativas.

Essa ressalva se torna necessária, pois os sujeitos aqui estudados se encontravam internados compulsoriamente em conformidade com determinações judiciais a eles imputadas, cujo delineamento amostral se deu mediante o critério que Leite (2008) denomina saturação.

Foram empregadas para a pesquisa teórica as categorias internação compulsória, drogadição, biopolítica e subjetividade, obtidas em artigos indexados e livros sobre o tema. Para a pesquisa empírica, 
foi utilizada como instrumento de coleta de dados a entrevista despadronizada, que segundo Leite (2008) se caracteriza por um diálogo feito face a face, sem um roteiro pronto, rígido, a ser seguido. Trata-se de um instrumento muito utilizado em pesquisas nas ciências sociais, já que não estabelece uma relação hierárquica entre o entrevistador e o entrevistado, mas uma interação, isto é, caso haja uma aceitação mútua, as informações surgirão genuinamente.

Durante o período da coleta, buscou-se mapear a instituição em seu funcionamento, despindo-se de uma pretensiosa configuração idealizada sobre o espaço em questão, bem como das pessoas que nele estão inseridas. Assim, buscou-se forjar, aos poucos, os sentidos ativos e as nuances que atravessavam e formatavam esse sistema de atendimento. Os matizes que contornavam a instituição ganharam outras cores e dimensões à medida que a pesquisa permitiu deixar se atravessar pelas forças que instituíam o espaço em questão.

Conforme as linhas territoriais eram sutilmente desfeitas, outras tantas foram alinhavadas entre barras fixas, para tensionar a flacidez de corpos modelados por estratégias biopolíticas e oceanos vivos, que se faziam vívidos através de teias elétricas do espaço físico da clínica. Chocar os sentidos visuais em meio a barras e cercas elétricas para flexibilizar e fazer vazar a vida como uma possibilidade: cartografar (Escóssia \& Tedesco, 2009).

Os resultados permitiram verificar, pelos estudos dos discursos acessados, que as engrenagens institucionais expressam formas de poder que reverberam nas vidas dos indivíduos entrevistados. Por fim, foi possível concluir que as estratégias de regulamentação da vida, seja pela judicialização, seja pela medicalização, anunciam um registro biopolítico que se impõe sobre os corpos de sujeitos que fogem da padronização dominante, que se efetiva na internação compulsória e nas práticas de judicialização da vida.

A análise foi realizada numa perspectiva do acionamento de uma analítica dos discursos, cuja abordagem tornou possível entender como se dão os modos de subjetivação e os processos subjetivos que movimentam e contornam a vida dos jovens submetidos à internação compulsória. Estes protagonizam uma escrita de manutenção e atualização de dispositivos biopolíticos imbricados no controle das subjetividades.

Neste sentido, aqui é apresentada uma reflexão sobre como as estratégias biopolíticas incidem no entre das organizações, visando apreender como elas envol- vem estes corpos através de representações curativistas. O campo teórico, a partir do qual tais práticas são estudadas, permite apreender que essas organizações revelam a expressão da captura dos modos de subjetivação e das formas de subjetividade, determinando-lhes um lugar no qual a vida deve ser mantida de forma reificada na perspectiva da lógica capitalística.

Por tratar-se de uma pesquisa de campo, foi possível a observação de diferentes situações referentes a esse grupo. Os informantes tiveram oportunidade de pensar e apresentar (produzir) suas ideias sobre temas que foram propostos, conforme as citações que ilustram os resultados a seguir. A análise dos dados obtidos teve como base um arcabouço teórico que permitiu o alcance do objetivo de refletir e compreender a problemática pesquisada (Chizzotti, 2008; Minayo, 2011), considerando que essa abordagem se aplica ao estudo das relações, dos desenhos, das percepções e das opiniões, produto das interpretações que os homens fazem a respeito de como vivem, constroem seus artefatos e a si mesmos. Sentem e pensam.

O estudo foi realizado em uma comunidade terapêutica para dependentes químicos, localizada no sul do estado do Espírito Santo, cuja meta foi encontrar novas possibilidades de reabilitação física e psicológica e de reinserção social dos residentes. É uma clínica que tem sido referência no tratamento de dependência química. Além de receber internações voluntárias, também realiza internações compulsórias, que atualmente ocupam o maior número de leitos da instituição. $\mathrm{O}$ cenário é propício à realização da pesquisa, pelo fato de ser um ambiente que recebe internações de todo o estado do Espírito Santo, possibilitando, assim, a coleta de material produzido por residentes de diferentes localidades. A pesquisa foi realizada com os residentes que estavam em tratamento no período da pesquisa neste estabelecimento por internação compulsória e que aceitaram assinar o Termo de Consentimento Livre e Esclarecido (TCLE). As falas dos jovens, trazidas para ilustrar a análise, foram identificadas com a palavra sujeito, seguida de numeração arábica para identificar entrevistados diferentes.

As delimitações amostrais dependeram de dois fatores: da adesão dos participantes da experiência, que aceitaram colaborar para a elucidação daquela experiência, e do critério de saturação de dados obtido a partir do período destinado à coleta. O critério de saturação, de acordo com Denzin e Lincoln (2006), determina o encerramento amostral pela cessação de 
inserção de novas informações, determinando a não inclusão de novos participantes na pesquisa a partir do momento que os dados coletados começam a apresentar redundâncias e repetições, deixando de ser relevante prosseguir com a coleta.

A pesquisa desenvolvida respeitou os trâmites éticos descritos na Resolução no 466/12 do Ministério da Saúde, Conselho Nacional de Saúde, Comissão Nacional de Ética em Pesquisa e suas complementares, que contém as diretrizes e normas de uma pesquisa envolvendo seres humanos com o CAAE 43578915.5.0000.50.65.

\section{Iniciando a conversa: a vida em cena}

Esta pesquisa se propõe a conhecer como se dão os processos de subjetividades de jovens em internação compulsória e estudar como se atualiza o processo de internação, a partir dos dispositivos legais e das determinações judiciais que incidem sobre essas vidas. O conceito de subjetividade na contemporaneidade tem sido relacionado ao de individualização, como se ambos fossem fenômenos unívocos. A subjetividade implica num processo mais amplo, em que múltiplos componentes se encontram envolvidos e interligados, sendo forjada num dado contexto histórico, político, social e econômico. Isso faz com que o sujeito se torne resultado de um processo aberto a mudanças, sendo produto e produtor desse processo.

Em meio a todas essas biotecnologias contemporâneas, tecem-se modos de sentir, perceber, existir e portar-se. Estes são chamados de modos de subjetivação, processos a partir dos quais são configuradas as formas de subjetividades. A subjetividade, então, seria uma forma e os modos de subjetivação as passagens, não existindo nenhuma contraposição entre ambas (Machado, 1999; Mansur \& Machado, 2014).

Acionar uma "analítica dos discursos" para estudar a subjetividade possibilita entender como se dão esses modos de subjetivação e os processos subjetivos que movimentam e contornam as vidas dos jovens submetidos à internação compulsória. Como as estratégias biopolíticas incidem no entre das organizações, envolvem estes corpos através de representações curativistas, impulsionando a elaboração desta pesquisa.

Dessa forma, adentrar no campo das políticas públicas para a drogadição foi uma alternativa necessária para pensar como esses sistemas, que normatizam uma determinada concepção de sujeitos, os tornam menos humanizados do que outros pelas condições de vida. Tais sujeitos não possuem voz nos espaços sobrepujados pelos saberes acadêmicos ou científicos, nos quais se produzem verdades e decisões referentes às suas vidas sem que possam contestá-las. Nas palavras de Caponi (2009) sobre a relação de possibilidades do biopoder, "vida nua, essa vida que as estratégias de biopoder consideram como não sendo digna de ser vivida" (p. 531).

Desde o século XIX, as reverberações políticas e sociais resultantes das revoluções industriais forjaram uma nova caricatura de poder. Tem-se a vigência de uma perspectiva filosófica antropocêntrica, positivista e liberal, para a qual um novo modelo de homem passa a imperar: o homem burguês. Michel Foucault, em sua obra Vigiar e punir (1987), demonstra que a produção da vida é pautada no biopoder e convoca ao entendimento dos direcionamentos do poder $\mathrm{e}$ de certo regime de economia de castigos e punições, que endossam a caricatura sociopolítica moderna, e ganhava força e vigor: a burguesia.

Foucault (1987) desenha as passagens entre distintos retratos socioculturais quando ressignifica a produção de sujeitos mais ou menos humanizados, ou melhor, sujeitos que merecem apenas pertencer mais ou menos à condição de existência humana, descrevendo a genealogia conceitual que será utilizada no decorrer desta pesquisa.

Dentre as tantas modificações socioculturais, destaca-se uma: o desaparecimento dos suplícios. Hoje existe uma tendência a desconsiderá-lo, talvez pela ênfase na ideia de humanização, que tende a se ater ao caráter essencialmente corretivo da pena desde o século XIX (Foucault, 1987).

Com o deslocamento do paradigma - que no período pré-capitalista e pré-burguês estava centrado em uma figura soberana que positivava a morte - para um período histórico em que o Estado positiva a vida que pode ser vivida, novas políticas de gestão desta vida se tornam evidenciadas e reconhecidas.

No Antigo Regime, a punição se dava por meio da exposição absurda dos corpos violentados como medida de castigo e afirmação do poder do soberano. Na modernidade, o poder passa a se expressar de forma sutil na gestão sobre os corpos e sobre as vidas. A demonstração pública, hiperbólica e espetaculosa veste outros sentidos com a ascensão do biopoder burguês.

Do ponto de vista do poder, quase sem tocar o corpo, a prisão suprime a liberdade ou uma multa tira os bens de um indivíduo, tal como a guilhotina suprimia a 
vida. A lei passa a ser aplicada agora não mais somente para que um corpo real e susceptível à dor sofra, mas para exercer o poder na forma de uma abstração da própria lei (Foucault, 1987). A lei passa a vigorar na modernidade de forma mais sutil sobre um sujeito jurídico, detentor de direitos, entre eles, o de existir.

Foucault (1987) relata que, ainda no século XIX, houve uma mudança no exercício dos direitos de soberania do Estado, regido agora sobre um poder de "fazer" viver e de "deixar" morrer. Com o advento do capitalismo, era necessário investir sobre os corpos de maneira que viessem a acompanhar o sistema de produção capitalista. Desse modo, fez-se necessário regulamentar a vida, cristalizando novos modos de ser e de estar no mundo, introduzindo a administração das produções subjetivas como matéria-prima do capital.

Segundo Foucault (2002), com essa mudança, o poder deixa de ser exercido através da "força", assumindo uma nova roupagem: o inimigo do soberano agora se torna inimigo da norma, sujeitos que precisam de correção e direcionamento. Nesse sentido, o autor afirma que a disciplina passa a se constituir como uma tecnologia de poder que se constrói sobre o corpo de cada indivíduo. Trata-se de um novo poder que se investe sobre o homem enquanto corpo e enquanto homem-sujeito.

As instituições de sequestro da subjetividade passam a fixar o sujeito-corpo nos "aparelhos" de normalização, transformando os homens em corpos maleáveis e moldáveis, os quais Foucault (2002) denomina corpos dóceis. O poder disciplinar torna esses corpos úteis quando intervém sobre eles. Nesse sentido, a internação compulsória - na atualidade - se transforma nessa modalidade de tecnologia de administração das produções subjetivas localizada entre os dispositivos de biopoder, à medida que integra mecanismos e estratégias políticas destinadas ao disciplinamento do corpo e à regulamentação da vida humana.

Tal medida se faz semelhante e reatualiza os episódios de um passado não muito distante, em que as práticas de internação visavam à retirada da sociedade daqueles que, de algum modo, eram vistos como um perigo ou risco social. O que dizer dos grandes leprosários e dos grandes manicômios? Neste sentido, a internação compulsória representa um retrocesso ao período anterior à Reforma Psiquiátrica, desconsiderando as lutas contra a internação para tratamento de doentes.

No Brasil, em tempos contemporâneos, o modelo asilar assume também outra faceta. A partir do discurso do cuidado, que dá continuidade à ideologia do encarceramento, miram-se novos alvos: os corpos viciados. A título de espaços especializados em tratamentos para dependência química, certas comunidades terapêuticas reinserem posturas similares às encontradas no modelo asilar, que funcionam pela lógica da exclusão e controle social de gestão da vida, retrocedendo a uma perspectiva ideológica que parecia superada.

Neste sentido, permite-se a ideologia do encarceramento de pacientes, como corpos viciados, geralmente pobres e em situação de extrema vulnerabilidade. Os espaços especializados, que têm sido utilizados no tratamento da dependência química, não raro fazem uso de posturas similares àquelas encontradas no modelo asilar tradicional, que funcionavam pela lógica da exclusão social, da gestão da vida e dos regimes políticos autoritários.

Este fenômeno multifacetado tem sido demasiado desafiador para a sociedade. Demanda investimentos em pesquisa para estudos científicos sobre respostas medicamentosas, terapêuticas, de análise dos laços sociais e afetivos constituídos entre pacientes, familiares e redes sociais e de amizade. Neste caso, não é menos importante que haja a inclusão de estudos sobre a realidade social e econômica desses sujeitos e suas particularidades, em face da atual conjuntura de crise econômica que nos afeta a todos e sobrecarrega de tensões os segmentos populacionais mais vulneráveis, com baixa escolaridade, desqualificação profissional e mais suscetíveis aos ditames do desemprego estrutural.

A aposta na perspectiva teórico-metodológica cartográfica possibilita um olhar ampliado sobre o processo de pesquisa, em que a práxis do pesquisador se encontra articulada à perspectiva dos sujeitos que participam da pesquisa. Em outras palavras, pode-se dizer com Escóssia e Tedesco (2009) que o desafio da cartografia é a investigação das formas associadas à sua dimensão processual no plano coletivo das forças moventes.

Nesse sentido, como Alvarez e Passos (2010) demonstram, não basta conhecer apenas um objeto que se refere a um mundo constituído. É necessário implicar-se com este mundo, com sua produção. Tomada por essa postura, que se desenha pela via afetiva, a intervenção da pesquisa se faz entre os sujeitos. E assim ela se fez.

No emergir das forças instituintes, os modos de subjetivação que habitavam a internação compulsória nas vidas e nas composições instituídas pince- 
laram territórios existenciais outros, com cadência, força e afirmação, em novas formas dimensionais que se tornaram expressivas, como diriam Deleuze e Guattari (1997).

Nos territórios existenciais, onde se expressava a entrevista como ferramenta, foi convocada uma interação. O contato com os sujeitos inseridos na internação compulsória por meio desse dispositivo fomentou torções em discursos de poder que haviam sido incorporados por estes sujeitos internos. Através dessas sutis torções, foi possível ouvir alguns rumores dessas vidas em cena.

\section{Subjetividades em descompassos: o imperativo do discurso de poder}

As histórias de vida aqui estudadas, dos jovens internados compulsoriamente, foram avassaladas por um fracasso de não conseguirem consumir plenamente formas de subjetividades capitalísticas. Trata-se de exemplo de subjetividades que já foram previamente produzidas em falta de suas garantias, sem conseguirem o ingresso na vida capitalística de aquisição de suas quinquilharias que lhes atribuiriam sentido.

Essa cartografia identificou que estes sujeitos se tornaram fracasso, restos descartáveis, sendo postos em medidas para serem capazes de se inserir no sistema vigente de produção de outra subjetividade - a neoliberal.

A internação compulsória se constitui num aparato que visa enquadrá-los num modelo de ser no qual suas existências se tornam funcionais: submissos ao poder, ao modo predominante de dominação da existência humana, registrado em uma forma de subjetivação determinada, como se expressa na frase, fragmento da narrativa: "Eu quero voltar a ser mãe, quero voltar a ser sobrinha, neta, entendeu?” (Sujeito 1).

Ou seja, no estágio em que essa vida se encontra, não é possível ser, não é possível existir, apenas sobreviver. Enquanto estiver viciada ou cumprindo medida de internação, estará impossibilitada de assumir outra forma de existência que não seja essa à qual se encontra condenada. Uma vez que a denominação viciada foi instituída para um público específico, não se pode nem ser mais reconhecido como sujeito. Como existir mãe se ela sequer existe como sujeito? Outro narrador reforça essa ideia: "Quando você é viciado, você deixa de ser gente" (Sujeito 4).

Para voltarem a ser gente, essas pessoas precisam ter suas vidas corrigidas, pois fracassaram em existir nos modos de existência forjados pelo Estado pelas formas jurídicas existentes, ideal de mundo que formata as formas de subjetividade produzidas pelo capital. Também não conseguiram um outro caminho. Não lhes foi possível outro acesso à própria subjetividade, a não ser pela via da drogadição, pela via de uma vida deteriorada, autodestruída.

A internação consiste num aparato ideológico que tenta forçá-los a cumprir o caminho do qual tentaram fugir: o de ser nada, dentro dos parâmetros instituídos de ser e estar no mundo, conforme os mecanismos capitalísticos. Para que isso aconteça, faz-se necessário que tais vidas assumam a forma que lhes tem sido exigida, tomando para si mesmas os discursos dominantes deste saber que lhes impõem um modo de existir, como nos leva a pensar a seguinte narrativa:

Lá fora, a gente fala noia, mas aqui dentro, a gente aprende que é adicto. Se você for visto como um noia lá fora, você não consegue emprego, você mal, mal, fala com as pessoas porque eles não te dão confiança, entendeu? (Sujeito 1).

Em meio a esse processo de forjar uma outra forma de subjetividade, que seja funcionalmente capitalística, esta fala indica que um dos primeiros passos para o tratamento seria reconhecer-se primeiro como um adicto, ou seja, um servo, um escravo da substância psicoativa, para depois ser apresentado a uma visão idealizada de si mesmo, e assim poder vir a ser aceito pela sociedade, por meio de um tratamento que o reconduz ao modelo idealizado e prescrito pelas normas e regras sociais.

Nesta lógica asséptica, ser um servo de uma substância psicoativa o torna menos degenerado do que ser um noia. Ser doente, reconhecer-se doente e assumir-se doente tem sido uma forma mais aceitável socialmente do que ser promíscuo. Ou seja, não se reconhecer como doente, não aceitar o caráter patológico da dependência produzida pelas drogas é melhor socialmente do que ser um viciado. Recusar a reconhecer a superioridade da ciência é inaceitável, revelando-se também uma forma de conformação que lhe possibilitaria um retorno à condição de um ser normal.

As pessoas que fazem uso de substâncias psicoativas ilícitas não deixam de se constituir sujeitos. Entretanto, essas subjetividades não são valorizadas, sendo, portanto, tornadas como produtos rejeitados pelo capital e pela sociedade e, por isso, precisam ser 
recicladas para produzirem, consumirem, amarem e viverem conforme o que se é exigido como aceitável.

A internação compulsória atua como uma forma de dominação e não como uma vontade de potência (que deveria ser), pois visa minar as resistências, seja por estratégias mais agressivas ou mais sutis, como expresso nesta fala: "A força uma hora vai cansar. A gente tem que ter a boa vontade, não a força de vontade, entende?" (Sujeito 1).

O sujeito precisa ter boa vontade para aceitar a forja de um corpo docilizado no sistema de produção de subjetividade capitalística, assim como capacidade para assumir um modo de existir que esteja nestes parâmetros de territórios existenciais, delimitados por um determinado modo de existir regido pelos dispositivos legais.

Observa-se que o processo de recuperação que se retrata nas falas a seguir consiste muito mais numa estratégia de docilização, numa micropolítica, do que numa proposta de mudança de vida, pois os sujeitos apenas reproduzem os discursos que thes são apresentados, como apontam os excertos de narrativas a seguir:

Sei que, enquanto estiver aqui, pelo menos não vou usar droga. Aqui ela não chega perto de mim. Mesmo que eu procure, não vou encontrar. O problema está lá fora. É lá que eu tenho que ser forte para não cair (Sujeito 6).

Meu maior crime foi me apaixonar pelas drogas, gostar mais delas que de mim, da minha família. Por isso estou preso nesse lugar (Sujeito 5).

Fico pensando onde eu cheguei, cara! Não é à toa que estou preso aqui dentro (Sujeito 6).

Quem está internado tem que entender que fez merda, por isso está aqui preso, sem liberdade, entendeu? Tem que reconhecer os erros para poder ser aceito de volta na sociedade (Sujeito 4).

Os depoimentos acima remetem à moralidade convencional, à culpa por não terem conseguido vencer a sedução da droga, ao medo de voltar a usá-la e à descriminação social por seu uso. Estes são alguns dos elementos que são trazidos à tona pelo uso das estratégias conservadoras e punitivas das medidas adotadas na experiência de internação compulsória aqui estudada.

Tais elementos conservadores e atuais, segundo Zimmer (2011), lembram as distintas tecnologias que foram utilizadas para a gestão dos corpos ao longo do tempo. As medidas de internação compulsória na atualidade dão continuidade ao modelo asilar, ao adestramento e ao controle da vida. Recoloca o que Foucault (2002) analisara sobre os hospitais psiquiátricos, considerados máquinas de curar por meio da exclusão social e de um tratamento punitivo de cunho moral, que visava a correção de comportamentos desviantes.

O depoimento de um residente aproxima a realidade de outrora ao modelo asilar de tratamento atual, caracterizando o comportamento moral ideal como equivalente à cura, como tem sido vivenciado atualmente por esses jovens em suas internações:

Eu quero sair no tempo certo, mas, se nas minhas avaliações eu estiver bem, eu tenho chance de sair antes. Quero sair pelo portão, não pelo muro. Quero sair curado, com minha moral restaurada. Quero poder ser aceito de volta (Sujeito 3).

Barros (1994) já atentara para o fato de que o manicômio nunca deixou de existir, mas sim persistiu ao longo dos anos mais limpo e mais modernizado, com outra fachada, com nomes e endereços que podem ser encontrados na contemporaneidade, como os centros de recuperação e as clínicas de tratamento para dependentes químicos. Tal avaliação se deve ao fato de esses espaços fazerem uso das mesmas práticas utilizadas no contexto asilar, funcionarem pela mesma ideologia de encarceramento e produzirem um discurso de cuidado que, ao mesmo tempo, pune e aprisiona a vida.

Esse raciocínio encontra-se na lógica estudada por Foucault (2002) sobre a disciplina como uma maneira específica de punir, expressando apenas uma lógica reduzida do tribunal, como consta nas falas a seguir: "Hoje sou mais disciplinado de diversas maneiras, entendeu?" (Sujeito 2); "Aqui é disciplinada a clínica, cheia de regras. Tem que ter comportamento adequado. Isso faz parte do tratamento e dá certo" (Sujeito 3).

Estes jovens conseguem identificar a relação entre disciplina e tratamento e a relação da disciplina utilizada pela clínica e as normas sociais que deveriam ser seguidas. Como não as seguiram em suas vidas anteriores à entrada na clínica, deverão aderir a elas ao sair para que sejam aceitos na sociedade de comportamentos submissos.

Ferreirinha e Raitz (2010) afirmam que as relações de poder se tornam mais visíveis através da disciplina quando estas estabelecem as relações opressor-opri- 
mido, mandante-mandatário, persuasivo-persuadido, comando-comandados. O depoimento a seguir endossa essa visão sobre a forma de tratamento adotada: "A gente precisa aprender o que falar aqui dentro, seja uns com os outros e, principalmente, com os profissionais que estão acima de nós, nos avaliando" (Sujeito 4).

De acordo com Foucault (1987), as instituições de sequestro, mencionadas anteriormente, prescrevem comportamentos e normas a serem seguidas, punindo aqueles que não se submetem às regras instituídas e às posições hierárquicas presentes nesse contexto. Nas sociedades disciplinares, existem mecanismos que incitam uma vida sob seus controles e vigilância. Atualmente, estes poderes produzem forças mais para ordenar a vida do que para destruí-la (Scopel \& Tavares, 2012). Nas falas a seguir, é possível observar como a produção da vida ordenada transparece no cotidiano relatado pelos entrevistados: "O jeito é ficar de boa, porque se você quiser aprontar, mostrar muita agitação, ansiedade, é sinal que você não está pronto para sair e ninguém quer ficar aqui muito tempo" (Sujeito 1).

Tal depoimento dá a entender como o tratamento precisa ser seguido à risca e, no caso de desobediência, pode-se esperar uma sanção. Neste sentido, revela-se como ineficaz. Segundo Castilho (2013), as medidas que permeiam tais procedimentos coercitivos, de restrição de liberdade e de internação compulsória são inadequadas ao tratamento de dependência química, pois não conseguem convencer o usuário a se rever espontaneamente.

Refletindo sobre a ideologia do castigo, verifica-se que é necessária a adesão voluntária, ativa e participativa do sujeito em obediência às normas da clínica. Abaixo, uma fala explicita essa lógica: “Se a pessoa não quiser se tratar, apenas fica presa aqui dentro, igual cadeia mesmo, cumprindo pena" (Sujeito 1).

As medidas de internação compulsória retomam o modelo asilar de tratamento, outrora direcionado para pessoas em sofrimento psíquico, atualizando a ideologia de exclusão social, em que esses espaços sempre funcionaram como prisão para os alienados, degenerados e as demais formas de subjetividade que não correspondiam aos ideais da sociedade capitalista naquele momento. Nesta, mantém-se a ideologia e atualiza-se a produção do discurso do cuidado.

Guattari e Rolnik (2005) destacam que a produção da subjetividade capitalística é o auge da produção da sociedade capitalista. O homem seria, nessa perspectiva, também um veículo consumidor de sub- jetividades que mantém o sistema vigente através do consumo de subjetividades capitalísticas, simultaneamente à produção das coisas. Ou seja, o homem contemporâneo tem também em seus corpos os registros das políticas de subjetivação produzidas no contexto biopolítico e disciplinar desejável para o bom funcionamento da lógica social.

Uma pessoa que se encontra encarcerada ou cumprindo medida de internação compulsória está inserida num espaço com suas próprias formas de subjetividade. Possui um jeito de amar, de viver, de se relacionar, uma maneira, um jeito, uma prática de existência. Este sujeito e seu modo de subjetivação estão ligados intrinsecamente às forças instituintes que o produziram. Vêm de um certo efeito de desterritorialização de certo território existencial, e provoca confrontos e é confrontado com outros modos de subjetivação mais adaptados no universo capitalístico.

Como um sentenciado, este sujeito é convocado a se produzir num território existencial outro. É convocado, por força de um poder legal, a se constituir na lógica daquela subjetivação que já não alcançou. Assim, o modo de subjetivação seria o devir, a passagem e a produção de novos territórios existenciais ou novas formas de subjetividade. Nesse sentido, observa-se aqui a reflexão produzida por Foucault (1987) sobre o poder das práticas jurídicas e judiciárias na determinação de subjetividades que, ao serem submissas ao Estado, passam a interferir e a determinar as relações humanas e, por conseguinte, a subjetividade dos indivíduos. As pessoas em cumprimento de medidas de internação compulsória estão restritas às biotecnologias do exercício de poder que arranjam a manutenção das chamadas instituições de sequestro.

Forjar modos de subjetivação em situação de cárcere - tendo em vista a absurda redução das possibilidades de invenção terapêutica de uma vida - tem se tornado veementemente mais oneroso. Com os corpos cerceados em instituições de sequestro, não se cria linhas de fuga, como se supõe.

Nestes espaços, em que as formas de subjetividade são talhadas sob o amparo do poder que neles impera, a manutenção de interesses econômicos e políticos dominantes fica mais evidente do que a finalidade terapêutica, resignando, assim, o território existencial dessas vidas a formas de subjetividade enrijecidas, cristalizadas, mortificadas, sujeitadas aos interesses da regulação e não da cura. Como dar passagem aos modos outros nesses espaços de fragilização? 
Sem conseguir dar passagem a outros devires - pelo fato de este sujeito estar imerso a um regime de manutenção do corpo e da vida sob controle -, as formas de subjetividade desse sujeito em internação compulsória já se encontram esgarçadas. As possibilidades de ele produzir novos movimentos instituintes, as maneiras outras de existir, aceitas socialmente na sociedade capitalista, são deveras constrangidas. Sempre restam dúvidas sobre os processos instituintes produzidos nas internações compulsórias: Até que ponto tais vidas vieram adoecidas para o cumprimento da internação compulsória? Até que ponto elas adoeceram pelos mecanismos de sequestro imbricados nestas instituições?

Essas questões são apontadas no decorrer do texto à medida que o pensamento é acionado. Diante dos encontros com os jovens encarcerados com escuta ativa e olhos sensíveis, deparamo-nos com formas de subjetividades cansadas: corpos que sustentam uma identidade para se fixarem ao regime de poder.

Pode-se dizer que há uma abstração sobre os modos possíveis de subjetivação, sem a possibilidade real de uma subjetividade individuada, na qual o processo de singularização do sujeito é impedido em detrimento de uma identidade alçada através das subjetividades capitalísticas. A lógica dessa identidade capitalística até permite uma segmentarização, desde que faça valer tal sistema de poder em que alguns podem ser deixados para morrer e outros não. Elementos significativos, tais como raça, classe social, idade, gênero, entre outros, legitimam esse arquétipo. Na esteira desse pensamento, Guattari e Rolnik (2005) endossam o argumento da existência de uma subjetividade mais ampla, uma subjetividade capitalística.

Neste sentido Machado e Lavrador (2010) chamam atenção sobre as formas como as políticas incidem sobre a vida e produzem formas de subjetividade, proliferando tecnologias políticas que investem na relação espaço-tempo da existência. Já Merhy (2013) observa que o alvo de tais tecnologias é a captura das diferentes formas de subjetividade, que se constituem como ameaças para o sistema capitalista, impondo uma forma de gestão da vida dos coletivos para alimentar o capital.

\section{Considerações finais: uma conversa que não se encerra aqui}

As medidas de internação compulsória, mesmo que involuntariamente, têm contribuído para a manutenção de resquícios de um modelo asilar de trata- mento, antes destinados a pessoas em sofrimento psíquico. Atualizam, assim, certas expressões de uma ideologia de exclusão social, na qual os "asilos de loucos" funcionaram para aprisionamento e ocultação (dos olhos da sociedade) de subjetividades consideradas alienadas, degeneradas e indesejáveis, que não correspondem aos ideais burgueses até hoje.

A pesquisa que deu origem a este artigo não está delimitada apenas às linhas que aqui se tecem, pois se trata de uma conversa que realmente não se encerrou aqui. Observou-se a relevância de algumas falas como reveladoras de um dispositivo a mais que revela aspectos de um processo de produção de resistências a um modo medicalocêntrico, higienista e serializador, que se reatualiza como medida terapêutica.

As falas dos jovens internos revelam a existência do dispositivo que acresce este modo discriminador tradicional. Trata-se de um dispositivo que se reatualiza como medida terapêutica, mas que não conduz a uma intervenção terapêutica genuína, pois determina a produção de resistências a tais abordagens entre os internos. Neste sentido, se revelam inócuas em seus objetivos de controle social.

Neste cenário de concepção limitada e distorcida sobre internação compulsória, tal perspectiva minimalista parece estar vulnerável a equívocos que marginalizam os internos em estratégias administrativas que sequestram suas vidas por um período fugaz, sendo percebida mais como punição do que como tratamento.

Afirma-se, portanto, que do ponto de vista político, tais discursos e práticas, capturados por uma engrenagem biotecnológica de poder, reiteram o cenário de exclusão social, evidenciando as desigualdades sociais e a violação dos direitos humanos: a internação compulsória coloca a vida numa cena de subjetividades em descompasso.

A concepção limitada e distorcida a respeito da internação compulsória, além de minimalista, parece estar vulnerável a equívocos, uma vez que trabalha com uma alternativa única de solução para o problema conforme a lógica do isolamento, da administração e da apropriação da vida das pessoas lá internadas.

Convém atentar-se para toda essa tensão política discutida e vivenciada - não apenas nessa pesquisa, mas também no que tange ao exercício das práticas profissionais - de que a drogadição se constitui num fenômeno multifacetado e demasiado desafiador para que seja tratado apenas de forma burocrática e regulamentadora. 
Considerando a tentativa das ciências em mensurar essa questão, ao deslocar os afetos para um segundo plano, além ou aquém de quaisquer mensurações quantitativas, são aplicados métodos que não conversam com a realidade desses sujeitos, abstraindo-os do contexto histórico, social e econômico em que estão inseridos.

Nossa aposta foi entender, ainda diante dessas estruturas de poder, que é possível produzir linhas de fuga; dar passagem às vicissitudes que se projetam na vida dos sujeitos implicados nestas condições. Isso significa considerar não apenas aquele que está submetido compulsoriamente a esse sistema (que sofre e/ou é responsável por esses jogos de força) que constitui o poder contemporâneo. Consiste também em atiçar linhas micropolíticas e/ou disparar outras.

Assim, este trabalho pretendeu contribuir para problematizar a concepção limitada e minimalista de tratamento designada internação compulsória, que pode favorecer equívocos na condução do tratamento, uma vez que se trabalha só com esta alternativa, que acaba contribuindo para a promoção de estímulos sociais à marginalização, à administração e à apropriação da vida das pessoas pelos preconceitos e estereótipos.

A partir dessa reflexão, aponta-se que o tratamento para dependentes químicos pode ter novas possibilidades a partir da estratégia da clínica ampliada e de utilização de diversos recursos outros da perspectiva psicossocial. Ultrapassando a terapia da abstinência e o controle das pessoas nos momentos mais agudos, a clínica ampliada é entendida como uma aposta que se faz na integração, na articulação e no reconhecimento de saberes multiprofissionais e interdisciplinares. Pode contribuir para produzir uma alternativa de atuação não apenas para profissionais da saúde mental, já que envolve uma concepção desafiadora também para gestores e trabalhadores no processo de construção de saúde.

\section{Referências}

Alvarez, J., \& Passos, E. (2010). Cartografar é habitar um território existencial. In E. Passos, V. Kastrup, \& L. Escóssia (Orgs.), Pistas do método da cartografia: pesquisa-intervenção e produção de subjetividade (pp. 131149). Sulina.

Barros, D. D. de. (1994). Cidadania versus periculosidade social: A desinstitucionalização como desconstrução do saber. In P. Amarante (Org.), Psiquiatria social e reforma psiquiátrica (pp. 171194). Fiocruz.

Bocco, F. (2009). Cartografias da infração juvenil. Abrapso Sul.

Caponi, S. (2009). Biopolítica e medicalização dos anormais. Physis: Revista de Saúde Coletiva, 19(2), 529-549. http://dx.doi.org/10.1590/S0103-73312009000200016

Castilho, E. W. V. (2013). A eficácia invertida da internação involuntária. In Conselho Federal de Psicologia (Org.), Drogas e cidadania em debate (pp. 3538). https:/ /bit.ly/3xafKFa

Cavalcante, M. B. P. T., Alves, M. D. S., \& Barroso, M. G. T. (2008). Adolescência, álcool e drogas: Uma revisão na perspectiva da promoção da saúde. Escola Anna Nery Revista de Enfermagem, 12(3), 555-559. https:// doi.org/10.1590/S1414-81452008000300024

Chizzotti, A. (2008). Pesquisa qualitativa em ciências humanas e sociais (2a ed.). Vozes.

Coelho, I., \& Barros, M H. (2014). Internação compulsória e crack: Um desserviço à saúde pública. Saúde em Debate, 38(101), 359-367. https://doi.org/10.5935/0103-1104.20140033

Deleuze, G., \& Guattari, F. (1997). Mil platôs: Capitalismo e esquizofrenia, Vol. 5. Editora 34.

Denzin, N. K., \& Lincoln, Y. (Orgs.). (2006). O Planejamento da pesquisa qualitativa: Teorias e abordagens. Artmed.

Escóssia, L., \& Tedesco, S. (2009). O coletivo de forças como plano da experiência cartográfica. In E. Passos, V. Kastrup, \& L. Escóssia (Orgs.), Pistas do método da cartografia: pesquisa-intervenção e produção de subjetividade (pp. 92-108). Sulina.

Ferreirinha, I. M. N., \& Raitz, T. R. (2010). As relações de poder em Michael Foucault: Reflexões teóricas. Revista de Administração Pública, 44(2), 367383. https://doi.org/10.1590/S0034-76122010000200008

Foucault, M. (1987). Vigiar e punir: Nascimento da prisão (27a ed.). Vozes.

Foucault, M. (2002). Microfisica do poder. Graal.

Guattari, F., \& Rolnik, S. (2005). Micropolítica: Cartografias do desejo. Vozes. 
Lei $n^{\circ}$ 10.216, de 6 de abril de 2001. (2001, 9 de abril). Dispõe sobre a proteção e os direitos das pessoas portadoras de transtornos mentais e redireciona o modelo assistencial em saúde mental. Diário Oficial da União, Seção 1.

Leite, F. (2008). Metodologia científica. Ideia.

Machado, L. A. P., \& Lavrador, M. C. (2010). As políticas que incidem sobre a vida. Estudos e pesquisas em psicologia, 1O(1), 118133. https://doi.org/10.12957/epp.2010.9022

Machado, L. D. (1999). Subjetividades contemporâneas. In M. E. B. de Barros (Org.), Psicologia: Questões contemporâneas (pp. 211-229). Edufes.

Mansur, T. S., \& Machado, L. A. D. (2014). Problematizando a noção de "vítima" de violência. Psicologia \& Sociedade, 26(spe), 183192. https://doi.org/10.1590/S0102-71822014000500019

Melo, J. R. F., \& Maciel, S. C. (2016). Representação social do usuário de drogas na perspectiva de dependentes químicos. Psicologia: Ciência e Profissão, 36(1), 7687. https:// doi.org/10.1590/1982-3703000882014

Merhy, E. (2013). Anormais do desejo: Os novos não humanos? Os sinais que vêm da vida cotidiana e da rua. In Conselho Federal de Psicologia (Org.), Drogas e cidadania em debate (pp. 0918). https://bit.ly/3dA2aTI

Minayo, M. C. S. (2011). O desafio do conhecimento: Pesquisa qualitativa em saúde. Hucitec.

Scopel, A. C., \& Tavares, G. M. (2012). As masmorras capixabas e o ronco surdo da batalha. Revista Polis e Psique, 2(1), 7997. https://doi.org/10.22456/2238-152X.29571

Zimmer, F. (2011). A internação compulsória: uma nova porta de entrada legal para o asilo [Dissertação de Mestrado, Universidade Federal do Espírito Santo]. Repositório Ufes. http://repositorio.ufes.br/handle/10/6733

\section{Linccon Fricks Hernandes}

Mestre em Políticas Públicas de Desenvolvimento Local pela Escola Superior de Ciências da Santa Casa de Misericórdia de Vitória (Emescam), Vitória - ES. Brasil.

E-mail: fricksjr@hotmail.com

(1) https://orcid.org/0000-0002-7642-3080

\section{Priscila Vescovi}

Mestre em Psicologia Institucional pela Universidade Federal do Espírito Santo (Emescam), Vitória - ES. Brasil.

E-mail: privescovi@hotmail.com

(1) https://orcid.org/0000-0001-5295-6731

\section{Túlio Alberto Martins de Figueiredo}

Mestre em Saúde Pública (1991) e doutor em Saúde Pública (1997) pela Faculdade de Saúde Pública da Universidade de São Paulo (FSP-USP), São Paulo - SP. Brasil.

E-mail: tulioamf.ufes@gmail.com

(1) https://orcid.org/0000-0002-6476-9009

\section{Raquel de Matos Lopes Gentilli}

Doutora em Serviço Social pela Pontifícia Universidade Católica de São Paulo (PUC-SP), São Paulo - SP. Brasil.

E-mail: raquel.gentilli@emescam.br

(1) https://orcid.org/0000-0003-1673-8440

Agradecimentos:

Fundação de Amparo à Pesquisa do Espírito Santo (Fapes).

Endereço para correspondência:

Escola Superior de Ciências da Santa Casa de Misericórdia de Vitória (Emescam). Avenida Nossa Senhora da 
Psicologia: Ciência e Profissão 2021 v. 41 (n.spe 4), e210219,1-12.

Penha, 2190, Santa Luíza. CEP: 29045-402. Vitória - ES. Brasil.

Recebido 01/08/2018

Aceito 25/11/2019

Received 08/01/2018

Approved 11/25/2019

Recibido 01/08/2018

Aceptado 25/11/2019

Como citar: Hernandes, L. F., Vescovi, P., Figueiredo, T. A. M., \& Gentilli, R. M. L. (2021). Internação Compulsória e vida em cena: Subjetividades em descompasso. Psicologia: Ciência e Profissão, 41 (n.spe 4), 1-12. https://doi. org/10.1590/1982-3703003210219

How to cite: Hernandes, L. F., Vescovi, P., Figueiredo, T. A. M., \& Gentilli, R. M. L. (2021). Involuntary commitment and life on the scene: Subjectives out of step. Psicologia: Ciência e Profissão, 41 (n.spe 4), 1-12. https://doi.org/10.1590/1982-3703003210219

Cómo citar: Hernandes, L. F., Vescovi, P., Figueiredo, T. A. M., \& Gentilli, R. M. L. (2021). Ingreso obligatorio y vida en escena: Subjetividades en descompaso. Psicologia: Ciência e Profissão, 41 (n.spe 4), 1-12. https://doi.org/10.1590/1982-3703003210219 